\title{
HUBUNGAN ANTARA BUDAYA ORGANISASI DAN GAYA KEPEMIMPINAN TERHADAP KEPUASAN KERJA DOSEN TETAP DI SEBUAH PERGURUAN TINGGI SWASTA DI DKI JAKARTA
}

\author{
Dwiki Ananto Yudo \\ Email : dwiki.ananto@perbanas.id
}

\begin{abstract}
Abstrak :Tulisan ini bertujuan untuk mengkaji hubungan antara variabel budaya organisasi dan variabel gaya kepemimpinan terhadap variabel kepuasan kerja. Penggunaan variabel tersebut berdasarkan penelitian terdahulu, yaitu: H. Teman Koesmono (2005), dan Ramlan Ruvendi (2005). Penelitian ini dilakukan di sebuah Perguruan Tinggi swasta di DKI Jakarta dengan jumlah responden sebanyak 75 orang dosen tetap, dengan menggunakan tools koefisien Rank Spearman melalui software SPSS 19. Hasil penelitian menunjukkan bahwa budaya organisasi dan gaya kepemimpinan memiliki hubungan yang positif dan signifikan terhadap kepuasan kerja dosen tetap, yaitu sebesar $r=0,835$ pada variabel budaya organisasi, dan $r=0,895$ pada variabel gaya kepemimpinan.
\end{abstract}

\section{Kata kunci : Budaya Organisasi, Gaya Kepemimpinan, Kepuasan Kerja, Dosen}

\section{PENDAHULUAN}

Sumber daya manusia merupakan salah satu asset yang paling berharga bagi sebuah perusahaan. Peranannya yang dapat menjadi pelaksana kebijakan dan kegiatan operasional perusahaan, menjadi alasan bagi sebuah perusahaan untuk dapat menjawab tantangan dalam mengelola sumber daya manusia yang dimiliki. Perusahaan dapat dengan mudah menjawab tantangan tersebut dengan adanya perkembangan manajemen sumber daya manusia belakangan ini. Salah satu pemicu semakin berkembangnya manajemen sumber daya manusia adalah adanya tuntutan dari karyawan untuk mendapatkan kesejahteraan baik moriil maupun materiil. Jika perusahaan tidak dapat memenuhi tuntutan dari karyawannya, perusahaan dapat saja kehilangan karyawannya karena ketidakpuasan kerja. Karyawan dapat malas-malasan dalam bekerja, tidak taat peraturan, demonstrasi, atau bisa saja memutuskan untuk meninggalkan perusahaan.

Salah satu hal yang dapat meningkatkan kepuasan kerja karyawan adalah faktor budaya organisasi. Faktor budaya organisasi sangat terkait dengan lingkungan organisasi yang meliputi rekan kerja, suasana kerja, pimpinan, dan faktor lain yang dapat mempengaruhi seseorang dalam bekerja. Selain budaya organisasi, gaya kepemimpinan juga dapat mempengaruhi kepuasan kerja seorang karyawan. Sebagai contoh, seorang pemimpin yang mau mendengarkan masukan dari karyawannya dapat menimbulkan sense of belonging dalam diri karyawan terhadap perusahaan, sehingga muncul kepuasan kerja dalam diri karyawan.

Dwiki Ananto Yudho, adalah Dosen Prodi Manajemen Perbanas Institute Jakarta 


\section{TINJAUAN PUSTAKA}

Menurut Robins (2011), budaya organisasi merupakan suatu sistem makna bersama yang dianut oleh anggota-anggota yang membedakan organisasi tersebut dengan organisasi lain. Budaya organisasi memiliki karakteristik primer yang bersama-sama menangkap hakikat dari suatu budaya sebuah organisasi. Penelitian ini akan mengacu pada teori karakteristik primer budaya organisasi Robbins (2011), hasil penyempurnaan dari teori yang telah dikemukakan oleh O'Reilly (1991) sebelumnya, meliputi : inovasi dan pengambilan resiko, perhatian ke rincian, orientasi hasil, orientasi orang, orientasi tim, keagresifan, kemantapan.

Kepuasan kerja sebuah organisasi dapat dipengaruhi oleh gaya kepemiminan dalam sebuah organisasi. Fleishman dan Peters (1962) dalam Sri Trisaningsih (2007) menyatakan bahwa gaya kepemimpinan merupakan pola perilaku konsisten yang diterapkan pemimpin melalui orang lain, atau pola perilaku yang ditunjukkan pemimpin pada saat mempengaruhi orang lain seperti yang dipersepsikan orang lain. Menurut Linda M. Randall (2012), kepemimpinan tradisional memiliki dua model, yaitu transaksional dan transformasional. Dalam penelitian ini digunakan model kepemimpinan tradisional yang dikemukakan oleh Linda M. Randall (2012) untuk membuat kuesioner.

Kepuasan kerja harus ada dalam diri setiap karyawan, agar mereka dapat meningkatkan kinerjanya. Menurut Martoyo (2007), kepuasan kerja adalah keadaan emosi seorang karyawan dimana terdapat titik temu antara besarnya balas jasa yang diberikan oleh perusahaan dengan apa yang diinginkan oleh karyawan tersebut. Kepuasan kerja seorang karyawan dapat diketahui, Gilmer (1996) dalam As'ad (2004) memberikan beberapa indikator yang mempengaruhi kepuasan kerja seorang karyawan, diantaranya adalah: peluang untuk maju, rasa aman dalam bekerja, besarnya gaji yang diterima, kondisi perusahaan dan manajemen, sistem pengawasan, faktor yang mempengaruhi pekerjaan, kondisi pekerjaan, lingkungan pekerjaan, komunikasi, dan fasilitas yang tersedia. Tulisan ini akan memfokuskan dimensi kepuasan kerja berdasarkan indikator-indikator yang disampaikan oleh Gilmer (1996) dalam As'ad (2004) yang dituangkan ke dalam butir-butir kuesioner.

\section{METODE}

Untuk dapat mempermudah memahami hubungan antara budaya organisasi $\left(\mathrm{X}_{1}\right)$, dan gaya kepemimpinan $\left(\mathrm{X}_{2}\right)$ terhadap variabel kepuasan kerja $(\mathrm{Y})$, dapat digambarkan dalam gambar sebagai berikut:

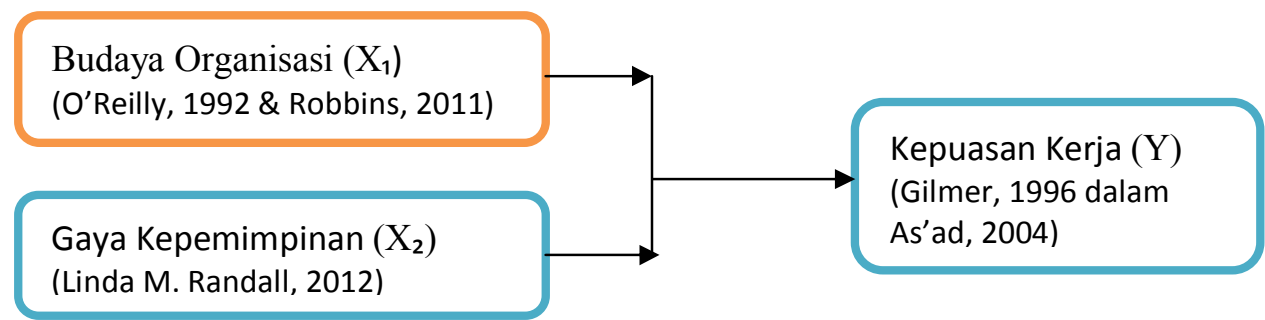

Gambar 1.Kerangka Pemikiran Keterkaitan Budaya Organisasi, dan Gaya Kepemimpinan Terhadap Kepuasan Kerja

Sumber: disusun oleh peneliti, 2013. 
Dari desain penelitian di atas dapat dilihat adanya hubungan antara Kepuasan Kerja (Y) dengan Budaya Organisasi $\left(\mathrm{X}_{1}\right)$ dan Gaya Kepemimpinan $\left(\mathrm{X}_{2}\right)$ sebagai variabel bebas yang diobservasi dalam penelitian ini. Adapun kemungkinan adanya variabel lain yang memiliki keterkaitan dengan variabel kepuasan kerja seperti kompensasi, komitmen, kompetensi, faktor eksternal, dan kompetensi bisnis tidak diobservasi dalam penelitian ini.

Metode penelitian pada penelitian menggunakan survey yang bertujuan untuk mengungkapkan informasi secara deskriptif dengan menggambarkan informasi berupa angka-angka hasil dari pengolahan data ke dalam bentuk yang mudah untuk dipahami. Hasil pengolahan data melalui survei dapat menggambarkan peranan masing-masing variabel, dan kausal berupa hubungan antara variabel budaya organsiasi, dan gaya kepemimpinan terhadap variabel kepuasan kerja dosen tetap yang terdapat pada Perguruan Tinggi Swasta di DKI Jakarta.

Penelitian ini menjadikan dosen di sebuah Perguruan Tinggi Swasta di DKI Jakarta sebagai populasinya. Total populasi pada penelitian ini sebanyak 264 orang yang terdiri dari 92 orang dosen tetap, dan 172 orang dosen tidak tetap. Sebagian dari populasi disebut sampel. Sampel yang diteliti merupakan dosen tetap sebanyak 92 orang yang diteliti dengan menggunakan teknik simple random sampling, dengan memperhatikan hirarki berdasarkan strukrur dan fungsi yang ada dalam organisasi sehingga diharapkan dapat merepresentasikan sebagian besar pendapat dari berbagai unsur. Besarnya sampel ditentukan dengan menggunakan rumus Slovin, yaitu: $\mathrm{n}=\mathrm{N} /\left(1+\mathrm{N} . \varepsilon^{2}\right)$. Dengan menggunakan error sampling sebesar $5 \%$, besar sampel minimal didapat adalah 74 atau dibulatkan menjadi 75 responden.

Penelitian ini dilakukan pada bulan Maret tahun 2013. Analisis kuantitatif dilakukan mengacu ke setiap dimensi/butir pertanyaan yang ada pada kuesioner yang telah dibagikan. Butir-butir pertanyaan yang terdapat pada kuesioner terdiri dari:

Tabel 1.

Variabel, Dimensi, dan Indikator

\begin{tabular}{|c|c|c|}
\hline VARIABEL & DIMENSI & INDIKATOR \\
\hline \multirow{14}{*}{$\begin{array}{l}\text { Budaya Organisasi } \\
\qquad\left(\mathrm{X}_{1}\right) \\
\text { (O’Reilly, 1991 dan } \\
\text { Robbins, 2011) }\end{array}$} & \multirow{2}{*}{$\begin{array}{l}\text { 1) Inovasi \& Pengambilan } \\
\text { Keputusan (Soal 1-2) }\end{array}$} & a) Dukungan atasan untuk berinovasi \\
\hline & & b) Menyampaikan gagasan baru \\
\hline & \multirow{3}{*}{$\begin{array}{l}\text { 2) Perhatian Kerincian (Soal } \\
3-5 \text { ) }\end{array}$} & a) Cermat terhadap rincian \\
\hline & & b) Analisa rincian dari atasan \\
\hline & & c) Mengerjakan rincian dengan baik \\
\hline & 3) Orientasi Hasil (Soal 6) & Fokus terhadap teknik dan proses \\
\hline & 4) Orientasi Orang (Soal 7-8) & a) Mempertimbangkan efek hasil \\
\hline & & b) Memperhatikan penyelesaian tugas \\
\hline & \multirow[t]{3}{*}{ 5) Orientasi Tim (Soal 9-11) } & a) Mendukung bekerja secara tim \\
\hline & & b) Mampu bekerja secara tim \\
\hline & & c) Menjalin hubungan yang akrab \\
\hline & \multirow[t]{2}{*}{ 6) Keagresifan (Soal 12-13) } & a) Siap bersaing dalam prestasi \\
\hline & & b) Menyukai persaingan \\
\hline & 7) Kemantapan (Soal 14) & Terbuka terhadap tuntutan perubahan \\
\hline
\end{tabular}


4 MODERNISASI, Volume 11, Nomor 1, Februari 2015

\begin{tabular}{|c|c|c|}
\hline VARIABEL & DIMENSI & INDIKATOR \\
\hline \multirow{14}{*}{$\begin{array}{c}\text { Gaya Kepemimpinan } \\
\left(\mathrm{X}_{2}\right) \\
\text { Linda M. Randall } \\
(2012)\end{array}$} & \multirow{3}{*}{$\begin{array}{l}\text { 1) Mendelegasikan Wewenang } \\
\text { (Soal 15-17) }\end{array}$} & a) Menjelaskan rincian tugas \\
\hline & & b) Memberi tugas sesuai minat \\
\hline & & c) Merumuskan tujuan bersama \\
\hline & \multirow[t]{4}{*}{ 2) Komunikasi (Soal 18-23) } & a) Mempunyai sifat menyenangkan \\
\hline & & b) Menghargai usulan bawahan \\
\hline & & c) Membudayakan adanya konsultasi \\
\hline & & d) Mengemukakan perasaan \\
\hline & \multirow[t]{2}{*}{ 3) Motivasi (Soal 24-27) } & a) Pemberian reward and punishment \\
\hline & & b) Memberi motivasi bawahan \\
\hline & \multirow[t]{5}{*}{ 4) Koordinasi (Soal 28-31) } & a) Perintah langsung kepada bawahan \\
\hline & & b) Mengutamakan kerja tim \\
\hline & & c) Memberi kesempatan berdiskusi \\
\hline & & d) Menegur bawahan \\
\hline & & e) Siap membantu bawahan \\
\hline \multirow{19}{*}{$\begin{array}{c}\text { Kepuasan Kerja (Y) } \\
\text { (Gilmer, 1996 dalam } \\
\text { As'ad, 2004) }\end{array}$} & \multirow{5}{*}{$\begin{array}{l}\text { 1) Job \& responsibility (Soal } \\
32-36)\end{array}$} & a) Menyenangi pekerjaan \\
\hline & & b) Tantangan pekerjaan \\
\hline & & c) Kejelasan tugas \& tanggung jawab \\
\hline & & d) Ketersediaan pedoman kerja / SOP \\
\hline & & e) Kejelasan akan target \\
\hline & \multirow{3}{*}{$\begin{array}{l}\text { 2) Evaluation/appraisal (Soal } \\
\text { 37-40) }\end{array}$} & a) Konsistensi dalam penilaian \\
\hline & & b) Obyektivitas dan transparansi \\
\hline & & c) Reward and punishment \\
\hline & \multirow[t]{3}{*}{ 3) Career path (Soal 41-46) } & a) Pelatihan / pengembangan pegawai \\
\hline & & $\begin{array}{l}\text { b) Pemahaman terhadap sistem } \\
\text { career }\end{array}$ \\
\hline & & c) Kesempatan dalam sistem career \\
\hline & \multirow{5}{*}{$\begin{array}{l}\text { 4) Work relationship (Soal 47- } \\
\text { 52) }\end{array}$} & a) Hubungan kerja pegawai \\
\hline & & b) Membangun tim dan sinergi \\
\hline & & c) Tanggung jawab bersama \\
\hline & & d) Berfikir solusi dan sukses bersama \\
\hline & & e) Efektifitas rapat dan diskusi \\
\hline & \multirow{3}{*}{$\begin{array}{l}\text { 5) Work condition (Soal 53- } \\
\text { 55) }\end{array}$} & a) Sarana kerja dan perlengkapan \\
\hline & & b) Ruang kerja dan tempat kerja \\
\hline & & c) Layanan dasar pekerjaan \\
\hline
\end{tabular}

Uji hipotesis yang dilakukan pada penelitian ini adalah dengan menggunakan Uji Parsial (Uji t) dan Uji Koefisiensi Parsial Parameter Model Regresi dengan menentukan formasi hipotesisnya sebagai berikut: 
a. Hipotesis $\mathrm{Nol}(\mathrm{H} 0)$ :

H0: tidak memiliki hubungan antara budaya organisasi dan gaya kepemimpinan terhadap kepuasan kerja dosen tetap Perguruan Tinggi IP.

b. Hipotesis Alternatif (H1)

H1: budaya organisasi dan gaya kepemimpinan memiliki hubungan yang positif terhadap kepuasan kerja dosen tetap Perguruan Tinggi IP.

Pada penelitian ini juga digunakan teknik uji statistik nonparametik dengan menggunakan teknik pengujian koefisien rank spearman. Alasan menggunakan teknik pengujian ini karena merupakan ukuran asosiasi yang menuntut kedua variabel diukur sekurang-kurangnya dalam skala ordinal, sehingga responden yang diteliti dapat diurutkan dalam dua rangkaian berturut-turut. Rumus koefisien rank spearman adalah:

$$
r_{S}=\frac{6 \sum d i^{2}}{n^{3}-n}
$$

Sumber: Husein Umar, 2008.

Keterangan:

$r_{s}=$ koefisien korelasi rank spearman yang menunjukkan keeratan hubungan antara unsur-unsur variabel $\mathrm{x}$ dan $\mathrm{y}$.

$\mathrm{di}=$ selisih rank data-data variabel $\mathrm{x}$ dan $\mathrm{y}$.

$\mathrm{n}=$ banyaknya subjek yang diteliti.

\section{PEMBAHASAN}

Tulisan ini akan menguraikan data tanggapan 75 responden yang telah disurvei mengenai kepuasan kerja pada sebuah Perguruan Tinggi swasta di DKI Jakarta. Mayoritas usia responden berada pada rentan usia 40 - 50 tahun ke atas dengan besar presentasi sebesar 31\%. Responden menurut jenis kelamin, pria sebanyak $49 \%$ dan wanita sebesar $51 \%$ dengan tingkat pendidikan terbesar yaitu S2 sebanyak 91\%. Menurut masa kerja, responden yang memiliki masa kerja 21 25 tahun memiliki jumlah terbanyak yaitu sebesar $40 \%$ dibandingkan dengan masa kerja lainnya.

Dari hasil analisis kuantitatif setiap butir kuesioner, kita dapat melihat nilai masing-masing variabel sebagai berikut:

Tabel 2.

Rekapitulasi Variabel Budaya Organisasi

\begin{tabular}{|l|l|c|c|}
\hline Variabel & Dimensi & Nilai & Keterangan \\
\hline Budaya Organisasi & (1) Inovasi dan Pengambilan Keputusan & 570 & Baik \\
\cline { 2 - 4 } & (2) Perhatian Kerincian & 945 & Sangat Baik \\
\cline { 2 - 4 } & (3) Orientasi Hasil & 241 & Baik \\
\cline { 2 - 4 } & (4) Orientasi Orang & 491 & Baik \\
\cline { 2 - 4 } & (5) Orientasi Hasil & 973 & Sangat Baik \\
\cline { 2 - 4 } & (6) Keagresifan & 653 & Sangat Baik \\
\cline { 2 - 4 } & (7) Kemantapan & 226 & Baik \\
\hline Total & & $\mathbf{4 0 9 9}$ & Baik \\
\hline
\end{tabular}

Sumber: data primer diolah, 2013. 
Nilai total rekapitulasi variabel budaya organisasi sebesar 4.099 dengan ratarata sebesar 293 tergolong baik. Hal tersebut menunjukkan bahwa sebagian besar responden merasa budaya organisasi yang terdapat di Perguruan Tinggi tersebut sudah baik.

Tabel 3.

Rekapitulasi Variabel Gaya Kepemimpinan

\begin{tabular}{|c|c|c|c|}
\hline Variabel & Dimensi & Nilai & Keterangan \\
\hline \multirow{4}{*}{$\begin{array}{l}\text { Gaya } \\
\text { Kepemimpinan }\end{array}$} & (1) Mendelegasikan Wewenang & 731 & Cukup \\
\hline & (2) Komunikasi & 1425 & Cukup \\
\hline & (3) Motivasi & 1032 & Baik \\
\hline & (4) Koordinasi & 911 & Kurang \\
\hline Total & & 4099 & Cukup \\
\hline
\end{tabular}

Sumber: data primer diolah, 2013.

Nilai total rekapitulasi gaya kepemimpinan sebesar 4.099 atau rata-rata sebesar 241 tergolong cukup. Hal tersebut menunjukkan dosen tetap di Perguruan Tinggi tersebut menilai gaya kepemimpinan, dalam hal ini Rektor, sudah cukup baik.

Tabel 4.

Rekapitulasi Variabel Kepuasan Kerja

\begin{tabular}{|l|l|c|c|}
\hline Variabel & Dimensi & Nilai & Keterangan \\
\hline Budaya Organisasi & (1) Job and Responsibility & 1353 & Baik \\
\cline { 2 - 4 } & (2) Evaluation/Appraisal & 924 & Kurang \\
\cline { 2 - 4 } & (3) Career Path & 1590 & Baik \\
\cline { 2 - 4 } & (4) Work Relationship & 1579 & Cukup \\
\cline { 2 - 4 } & (5) Work Condition & 789 & Baik \\
\hline Total & & $\mathbf{6 2 3 5}$ & Baik \\
\hline
\end{tabular}

Sumber: data primer diolah, 2013.

Nilai total rekapitulasi variabel kepuasan kerja sebesar 6.235 atau rata-rata sebesar 260 tergolong baik. Hal ini menunjukkan bawa responden merasa puas selama bekerja di Perguruan Tinggi tersebut.

Setelah mendapatkan nilai rekapitulasi masing-masing variabel kuesioner, langkah selanjutnya adalah mengukur nilai reliabilitas kuesioner dengan menggunakan rumus Alpha Cronbach's. Sebuah kuesioner termasuk dalam kategori reliable apabila nilai Alpha Cronbach's yang dihasilkan lebih besar dari 0,8. Berikut hasil uji reliabilitas dengan menggunakan software SPSS 19 for windows:

Tabel 5.

Cronbach's Alpha

\begin{tabular}{|l|l|}
\hline Cronbach Alpha & Nof Items \\
\hline 0,987 & 55 \\
\hline
\end{tabular}

Sumber: output spss, 2013

Pada uji validitas yang dilakukan dengan menggunakan SPSS 19 for windows, nilai koefisen korelasi semua butir pertanyaan yang terletak pada kolom 
"Corretcted Item Total Correlation" lebih besar dari 0,240. Dengan demikian dapat disimpulkan bahwa semua butir petranyaan pada kuesioner bagian ekspektasi sudah valid.

Pada analisis pengujian hipotesis, penulis menggunakan teknik pengujian koefisien rank spearman, karena penggunaan teknik pengujian ini merupakan ukuran asosiasi yang menuntut kedua variabel diukur sekurang-kurangnya dalam skala ordinal sehingga objek yang dipelajari dapat dirangking dalam dua rangkaian berturut-turut. Berikut adalah hasil pengujian koefisien rank spearman dengan menggunakan software SPSS 19 for windows:

Tabel 6.

Pengujian Hipotesis Rank Spearman

\begin{tabular}{|c|c|c|c|c|c|}
\hline & & & $\begin{array}{c}\text { Budaya } \\
\text { Organisasi }\end{array}$ & $\begin{array}{c}\text { Gaya } \\
\text { Kepemimpinan }\end{array}$ & $\begin{array}{l}\text { Kepuasan } \\
\text { Kerja }\end{array}$ \\
\hline \multirow[t]{9}{*}{ Spearman's rho } & Budaya Organisasi & $\begin{array}{l}\text { Correlation } \\
\text { Coefficient }\end{array}$ & 1 & $.783^{* *}$ & $.835^{* *}$ \\
\hline & & Sig. (2-tailed) & & 0 & 0 \\
\hline & & $\mathrm{N}$ & 75 & 75 & 75 \\
\hline & $\begin{array}{l}\text { Gaya } \\
\text { Kepemimpinan }\end{array}$ & $\begin{array}{l}\text { Correlation } \\
\text { Coefficient }\end{array}$ & $.783^{* *}$ & 1 & $.895^{* *}$ \\
\hline & & Sig. (2-tailed) & 0 & & 0 \\
\hline & & $\mathrm{N}$ & 75 & 75 & 75 \\
\hline & $\overline{\text { Kepuasan Kerja }}$ & $\begin{array}{l}\text { Correlation } \\
\text { Coefficient }\end{array}$ & $.835^{* *}$ & $.895^{* *}$ & \\
\hline & & Sig. (2-tailed) & 0 & 0 & \\
\hline & & $\mathrm{N}$ & 75 & 75 & 75 \\
\hline
\end{tabular}

Sumber: output spss, 2013.

Dari hasil pengujian di atas, diperoleh taraf signifikansi 0,000 yaitu $<0,05$ yang berarti menolak H0. Oleh karena itu hasil menunjukkan bahwa H1 diterima, berarti terdapat hubungan antara budaya organisasi dan gaya kepemimpinan terhadap kepuasan kerja. Dengan kata lain, budaya organisasi dan gaya kepemimpinan memiliki hubungan yang positif terhadap kepuasan kerja. Variabel yang memiliki hubungan paling dominan terhadap kepuasan kerja adalah variabel gaya kepemimpinan yang memiliki nilai 0,895 .

Hasil analisis hipotesis tersebut dapat terjadi karena adanya budaya akademik dan gaya kepemimpinan partisipatif yang dapat diterima oleh dosen tetap Perguruan Tinggi tersebut. Berdasarkan hasil observasi penulis, Perguruan Tinggi tersebut saat ini sudah mengalami transformasi yang positif dari periode-periode sebelumnya. Hal ini dapat dilihat dari adanya peningkatan sistem penilaian dosen, terbentuknya Direktur Pusat Penjaminan Mutu dan Kepatutan, serta terbentuknya Biro Marketing.

Budaya akademik yang terdapat pada Perguruan Tinggi ini tercernin dalam aktivitas rekturmen tenaga pengajar yang linear dengan mata kuliah yang diajarnya, pengawasan kualitas belajar-mengajar yang diberikan dosen melalui kuesioner 
yang diedarkan ke seluruh mahasiswa, peningkatan kualitas penelitian melalui jurnal, pengadaan pelatihan-pelatihan bagi dosen tetap, serita peningkatan kurikulum pendidikan yang tertuang dalam alur akademik dan perubahan bobot nilai setiap mata kuliah.

Gaya kepemimpinan yang terdapat pada Perguruan Tinggi ini merupakan gaya kepemimpinan transaksional. Hal tersebut tercermin dalam tindakan pemimpin yang memberikan penghargaan kepada dosen yang berprestasi baik karena sudah mengabdi dalam waktu yang cukup lama, maupun atas prestasi yang diraihnya dalam bidang akademis. Selain reward, pimpinan juga menjalankan punishment kepada dosen yang terbukti melakukan pelanggaran seperti korupsi, dan juga yang terbukti melakukan plagiat pada karya tulisnya.

Apabila penelitian ini dibandingkan dengan penelitian sebelumnya, maka akan tampak perbandingan sebagai berikut:

Tabel 7.

Rekapitulasi perbedaan hasil penelitian terdahulu

\begin{tabular}{|l|c|c|c|l|}
\hline \multirow{2}{*}{ Peneliti } & \multicolumn{3}{|c|}{ Variabel Penelitian } & \multicolumn{1}{|c|}{$\begin{array}{c}\text { Hasil } \\
\text { Penelitian }\end{array}$} \\
\cline { 2 - 4 } & $\mathrm{X}_{1}$ & $\mathrm{X}_{2}$ & $\mathrm{Y}$ & Kepuasan \\
$\begin{array}{l}\text { Hoesmono } \\
\text { Kurnal, 2005) }\end{array}$ & $\begin{array}{c}\text { Budaya } \\
\text { Organisasi }\end{array}$ & $\begin{array}{l}\text { Berpengaruh } \\
\text { sebesar 1,183 }\end{array}$ \\
\hline $\begin{array}{l}\text { Ramlan } \\
\text { Ruvendi } \\
\text { (Jurnal, 2005) }\end{array}$ & Imbalan & $\begin{array}{c}\text { Gaya } \\
\text { Kepemimpinan }\end{array}$ & $\begin{array}{c}\text { Kepuasan } \\
\text { Kerja }\end{array}$ & $\begin{array}{l}\text { Pengaruh Sig } \\
\text { Determinasi } \\
0,549\end{array}$ \\
\hline $\begin{array}{l}\text { Dwiki Ananto } \\
\text { Yudo (Tesis, } \\
\text { 2013) }\end{array}$ & $\begin{array}{c}\text { Budaya } \\
\text { Organisasi }\end{array}$ & $\begin{array}{c}\text { Kepema } \\
\text { Transaksional }\end{array}$ & $\begin{array}{c}\text { Kepuasan } \\
\text { Kerja }\end{array}$ & $\begin{array}{l}\text { Hubungan Sig } \\
\text { Determinasi } \\
0,895\end{array}$ \\
\hline
\end{tabular}

Sumber: data primer diolah, 2013.

\section{KESIMPULAN}

1. Hasil uji hipotesis yang menyebutkan 'budaya organisasi memiliki hubungan yang positif terhadap kepuasan kerja' dapat diterima. Hal tersebut memperkuat penelitian H. Teman Koesmono (2005) yang dilakukan di Sub Sektor Industri Pengolahan Kayu Skala Menengah di Jawa Timur. Pada penelitian tersebut dapat disimpulkan bahwa budaya organisasi memiliki pengaruh langsung secara positif terhadap kepuasan kerja.

2. Dari hasil pengujian hipotesis yang menyebutkan 'gaya kepemimpinan memiliki hubungan yang positif terhadap kepuasan kerja' dapat diterima. Dengan begitu, hasil uji hipotesis ini dapat memperkuat penelitian yang dilakukan oleh Ramlan Ruvendi (2005) yang mengungkapkan adanya pengaruh yang signifikan antara gaya kepemimpinan terhadap kepuasan kerja pegawai BBIHP.

3. Gaya kepemimpinan yang terdapat pada salah satu Perguruan Tinggi swasta di DKI Jakarta merupakan gaya kepemimpinan transaksional. Hal tersebut bisa ditunjukkan dari hasil penelitian yang menunjukkan komponen reward and punishment lebih kuat dibandingkan dengan komponen lainnya. Oleh karenanya, sebaiknya Perguruan Tinggi ini meningkatkan perhatian secara 
personal kepada dosen tetap, agar meraka bisa lebih maksimal dalam memberikan kontribusinya untuk Perguruan Tinggi.

\section{DAFTAR PUSTAKA}

Anoraga, Pandji. 2004. Manajemen Bisnis. Cetakan Ketiga. Rineka Cipta. Jakarta.

Anthony, Nyberg. 2010. Retaining your high performers: Moderators of the performance-job satisfaction-voluntary turnover relationship. Journal of Applied Psychology. Vol. 95, Iss. 3; pg. 440. Washington.

As'ad, M. 2004. Seri Ilmu Sumber Daya Manusia Psikologi Industri. Edisi Keempat. Cetakan Kesembilan. Jogjakarta : Liberty.

Campbell, Dean. 2003. Leadership and Academic Culture in the Senate President. The American Behavior Scientist Journal Vol. 46 No. 6 March.

David, Fred R. 2004. Manajemen Strategis, Konsep. Edisi Ketujuh. Prehallindo. Jakarta.

Davis, Keith. 1985. Human Behavior at Work: Organizational Behavior. Mc.Graw Hill. New York.

Ferdinand, A.T. 2006, Metode Penelitian Manajemen. BP Undip. Semarang.

Gibson, James L, Jhon M. Ivancevich dan James H. Donelly Jr. 1999. Organisasi dan Manajemen: Perilaku, Struktur dan Proses. Erlangga. Jakarta.

Hair, Joseph F. et al. 1998. Multivariate Data Analysis. Prentice-Hall,inc. New Jersey.

Handoko, H. 2001. Manajemen Personalia dan Sumber Daya Manusia. Edisi 2, BBPE. Yokyakarta.

Handoko, T. Hani. 2003. Manajemen. Edisi Kedua. Penerbit Liberty. Yogyakarta.

Hasibuan, Malayu S. P. 2005. Manajemen Sumber Daya Manusia. Penerbit PT. Bumi Aksara. Jakarta.

Hermansah. 2010. Penghargaan sebagai Bentuk Apresiasi kepada Pegawai. (online), (http://economy.okezone.com/read/2010/01/19/23/295455/23/penghargaan -sebagai-bentuk-apresiasi-kepada-pegawai).

Herujito, Yayat M. 2001. Dasar - dasar Manajemen. Penerbit PT Graznido. Jakarta. 
10 MODERNISASI, Volume 11, Nomor 1, Februari 2015

Jamaluddin, N. 2011. Analisis Pengaruh Kepemimpinan dan Budaya Organisasi Terhadap Kinerja Karyawan Pada PT. Mopoli Raya Medan. Universitas Sumatera Utara. Medan.

Jewell L.N \& Siegall M. 1990. Contemporary Industrial and Organizational Psychology. $2^{\text {nd }} E d$, West Publising Company. New York.

Johan, Rita. 2002. Kepuasan Kerja Karyawan Dalam Lingkungan Institutusi Pendidikan. Jurnal Pendidikan Penabur, No. 1 Th. 1 Maret.

Julitriarsa, Djati dan John Suprihanto. 1998. Manajemen Umum, Sebuah Pengantar. Edisi Pertama, Cetakan Ketiga. BBFE. Yogyakarta.

Koesmono, Teman. 2005. Pengaruh Budaya Organisasi Terhadap Motivasi dan Kepuasan Kerja serta Kinerja Karyawan pada Sub Sektor Industri Pengolahan Kayu Skala Menengah di Jawa Timur. Jurnal Ekonomi Manajemen. FE Universitas Kristen Petra.

Kreitner, Robert dan Angelo Kinicki. 2003. Perilaku Organisasi. Salemba Empat. Jakarta.

Martoyo, Susilo. 2007. Manajemen Sumber Daya Manusia. Edisi Kelima. BPFE. Yogyakarta.

Marzuki. 1995. Metodologi Riset. Hanindita Offset. Yogyakarta.

Moeljono, Djokosantoso. 2005. Budaya Organisasi Dalam Tantangan. Penerbit PT. Elex Media Komputindo. Jakarta.

Mozaffari, Neda et al. 2012. Study of Organizational Culture of Departments of Education in Isfahan Province in Academic Year 2010-11 Based on Denison Model. International Journal of Business and Social Science Vol. 3 No. 4.

Noe, dkk. 2011. Manajemen Sumber Daya Manusia: Mencapai Keunggulan Bersaing. Salemba Empat. Jakarta.

Nugraheni, Fitri. 2007. Wajah Konflik Dalam Organisasi; Penguasaan Manajemen Konflik Oleh Pemimpin. Jurnal Analisis Manajemen Vol. 2 No. 1.

Pace, R. Wayne dan Don F Faules. 2001. Komunikasi Organisasi. Rosdakarya. Bandung.

Poerwadarminta, Wilfridus Joseph Sabarija. 2008. Kamus Besar Bahasa Indonesia: Pusat Bahasa. Gramedia Pustaka Utama. Jakarta.

Prasetyo, Edhi. 1997. Pengaruh Kepuasan dan Motivasi Tehadap Produktivitas Karyawan Riyadi Place Hotel di Surakarta. Tesis. Program Pasca Sarjana Universitas Muhammadiyah. Surakarta.

Randall, Linda M. 2012. Transforming University: A Study of Process Leadership. Academy of Educational Leadership Journal, Volume 16 Number 2. 
Riduwan. 2005. Skala Pengukuran Variabel-Variabel Penelitian. Cetakan Ketiga. Alfabeta. Bandung.

Robbins, Stephen P. 2001. Organizational Behavior. Upper Saddle River. PrenticeHall Inc. New Jersey.

Robbins, Stephen F. 2002. Perilaku Organisasi, Konsep Kontroversi dan Aplikasi. PT. Prehallindo. Jakarta.

Robbins, Stephen P dan Timothy A. Judge. 2011. Organizational Behavior. Pearson. USA.

Robbins, Stephen P. 1998. Organizational Behavior: Concepts, Controversies, Applications. $8^{\text {th }}$ edition, PrenticeHall. USA.

Ruvendi, Ramlan. 2005. Imbalan dan Gaya Kepemimpinan Pengaruhnya terhadap Kepuasan Kerja Karyawan di Balai Besar Industri Hasil Pertanian Bogor. Jurnal Ilmiah Binaniaga, Vol. 1 No. 1.

Sekaran, Uma. 2006. Metodologi Penelitian Untuk Bisnis. Salemba Empat. Jakarta.

Siagian, P. Sondang. 2002. Manajemen Sumber Daya Manusia. Cetakan Kesembilan. Penerbit Bumi Aksara. Jakarta.

Singarimbun, Masri. 1991. Metode Penelitian Survei. LP3ES. Jakarta.

Sule, Ernie Tisnawati dan Kurniawan Saefullah. 2004. Pengantar Manajemen. Edisi Pertama. Cetakan Pertama. Prenada Media. Jakarta.

Sunarto. 2004. Perilaku Organisasi. Penerbit AMUS. Yogyakarta.

Sutrisno, Edy. 2007. Manajemen Sumber Daya Manusia. Kencana. Jakarta.

Sweeny, Paul D and Dean B McFarlin. 2002. Organizational Behavior: Solutions for Management. McGraw-Hill Irwin. USA.

Syvana, Andi. 2002. Pengaruh Gaya Kepemimpinan Terhadap Kinerja dan Kepuasan Kerja Anggota Polri Polda Metro Jaya. Jurnal Magister Manajemen. Universitas Terbuka. Jakarta.

Thoha, Miftah. 2003. Kepemimpinan dalam Manajemen. Rajawali Pers. Jakarta.

Trisnaningsih, Sri. 2007. Independensi Auditor dan Komitmen Organisasi Sebagai Mediasi Pengaruh Pemahaman Good Governance, Gaya Kepemimpinan, dan Budaya Organisasi Terhadap Kinerja Auditor. Jurnal Simposium Nasional Akuntansi X, Juli.

Winardi. 2000. Kepemimpinan Dalam Manajemen. Rineka Cipta. Jakarta. 
12 MODERNISASI, Volume 11, Nomor 1, Februari 2015

Wirda, Fisla dan Tuti Azra. 2007. Pengaruh Budaya Organisasi Terhadap Kinerja Karyawan Politeknik Negri Padang. Jurnal Ekonomi dan Bisnis Vol. 2 No. 1. 